\title{
Relating Continuity and Change to the Tabasaran of Daghestan
}

\section{Lorraine Ross}

Each time I return home to the Canadian Alberta prairie, I do so in part, to a different era for it appears that over two generations, change was somewhat slow. Though at first a frugal simple life with close ties to the land was indeed a necessity, it now seems more psychological. With stubbornness and steadfastness to a way of life, a pioneer spirit still prevails as my parents continue on with their pattern of life.

Carrying in the coal for my father one frigid winter night, I thought about the repetition of life patterns since my grandparents' immigration to Canada from Poland and how easily I could fall into similar ways to the last two generations, continuing the pattern in which I had grown up. In the repetition of simple acts the past was brought forward to the present. Indeed, the past lay present in symbolic form as I entered the small room stepping on a braided rug where here and there, I recognized pieces of an old worn blouse, some pairs of socks, and one of my brother's shirts. Working color patterns together from worn clothes saved up for the purpose, each rug my mother wove together was always a container of memories, as well as being new possibilities for her designs.

Participation in the everyday events of this way of life gave comprehension, and even though it may have appeared to change very little over time, each period brought new prevailing conditions with new choices and possibilities. My steps could never really be the same as those of prior generations. My interpretation of possibilities within the setting was shaped by my experience within it, by my understanding of its reality--that elusive, shifting veil so dependent on quotidian events.

The myriad of events and surroundings which form the elusive quality of lived reality could be but a continuous buzzing noise were it not for the potential of the symbol to give order and meaning to our experience. Cultural artifacts bear witness to the human need to link with other human beings--they can be a form of knowing with whom and with what one is connected. Such objects tie together a family, a community, a people. They are an integral part of the constitutive narrative of the community, often embodying several layers of meaning at once, thereby proving to be rich symbols. The more layers of meaning that have accrued to a symbol for a group of people, the wider its resonance within the community.

If artists have the intention to convey to others their original experience, then there must be some knowledge of the visual symbol system, 
such as its conventions, and vocabulary. Such guides, conventions and requirements of images may vary from culture to culture. Artists, as part of a community, may assist in the maintenance of the constitutive narrative as they continue to use resonant symbols within their images.

Slavic minority immigrants did journey forth to the Canadian prairies in significant enough numbers to leave their ethnicity indelibly etched within many communities. Even now, two and three generations away from those dominated by the Soviet regime, a Slavic identity still remains visible in the Canadian prairie population. As part of that group two generations later, it seems particularly apt that I look in on a people who have also persisted through Soviet domination. It is to the area of Daghestan, located within the country of Russia, that I turn to search for the constitutive narrative encrusted in the symbols and rhythms of Tabasaran people's community life.

The Tabasaran are one of the more numerous groups of mountain people who occupy villages high in the Northern Caucasus mountains. They continue to pass their accumulated traditions and understanding of over 1000 years of living to each new generation. Today they inhabit a richly designed architecture with motifs from very old traditions. It is not only the arrangement and design of physical space which reflect their adaptations and beliefs through time, but like any other ethnic group, they have objects whose traditional forms of expression resonate with their identity. For the Tabasaran, this is realized particularly through the ancient craft of weaving. The making of such objects continues to link them to each other, to the community and to the history of the land itself. Each moment of creating renews habits, customs and life rhythms in an affirmation of Tabasaran people.

Toiling over their work, women weave together, not merely strands of wool, but strands of Tabasaran life. In earlier times this weaving activity fulfilled practical needs, as well as aesthetic purposes; Earthen floors needed to be defended from the cold and clothes needed to be designed. Other uses for fine weaving were in mural tapestry, saddle bags and belts for carrying jugs. All such goods were imbued with the symbols and understanding of Tabasaran culture.

Weaving fulfilled several social purposes as well, since folklore, skills and designs were passed on from generation to generation as artists labored together. It was customary for girls of seven or eight to help their mother weave so that by the time they married they would have several carpets, comprising the dowry. (Kerimov et al., 1984) Each clan had a unique design which became modified over generations as gifted weavers added motifs of their own invention.

Several factors historically operated in conjunction with each other to keep women's weaving very emblematic of Tabasaran culture. Under moslemic influence, women had always remained more isolated in their villages since they had maintained the home, while men traded goods or 
took care of livestock in the lowlands during the winter. Since women did not come into contact with neighboring groups, each village eventually had very original features in the design, so that it was possible for the Caucasian people to identify the wearer of a particular woven shoe design or cloth style as originating from a specific village. Potential assimilation of groups, and hence designs, was further inhibited by constant rivalry over pasture lands owned by clans, leading to divisions among the Tabasaran as well as between the Tabasaran and other Caucasian peoples. Woven goods, along with other artistic products, were used as commodities in trade centers. If a particular village design became popular, it was less likely to change rapidly because it heightened the group's identity and in this way, also served to resist assimilation by other neighboring groups.

The correspondence of Tabasaran designs with customs, belief systems, and social practices is probably why the Soviet government's desired industrialization of such artifacts was extremely slow to take place, or in some instances did not happen. Certainly the Soviet policy brought about adaptation of form, sometimes encouraging production, for example, when commercial dyes were introduced to weaving, and at times making production more difficult, for example, when they encouraged crops which did not maintain a special type of sheep needed for felt production.

In spite of influences from centuries of invaders, the Tabasaran maintain stronger links with other Caucasus mountain groups than with the dominant Soviets. Today rural dwellers retain many markers of ethnicity, displaying great fondness for decorating dwellings with carpets, reversible rugs, runners and mats. It is common to find high necked decorative pitchers, mountain landscape painting, embroidery with ethnic decoration, or horns mounted in silver. Contrary to the hopes and wishes of the Soviet regime that the Tabasaran become Russified, artisans continue to produce images that speak to their own identity.

Art as cultural artefact must be combined with cultural behavior and cultural knowledge in order to go beyond a mere explicit knowledge of the art form. The setting, or context, as well as use and value of the artefact among the community members, become layers which can reveal tacit knowledge. Thus one pays attention not only to color relationships, or to the shapes and materials of the art form, but to how or when some item may be worn or used, to who may use or possess it, even to the surrounding topography--ail have the potential to be richly entwined within our understanding of the art forms. Among the Tabasaran, then, understanding is to be found on the dusty mountain roads, in the trade of the market and in the daily living within Tabasaran homes, for it is explicit and tacit knowledge of Tabasaran culture which gives rise to the richly patterned, multi-colored textiles.

The sparsity of actual knowledge and understanding of the Tabasaran within the western world is increasingly obvious. Looking at the slides I had made of the Tabasaran work I found in books, I felt much as I imagined Diana 
Korzenik to feel as she sat before the drawings of the Cross children, seeking to write about the passion for drawing in 19th century America. She writes:

It seemed to me that if only it were possible to interpret the meaning and hope of drawing in one particular life, I could animate otherwise rather $d r y$ generalizations. Without such detail, the passion for learning to draw would be as devoid of meaning as a deeply felt dream retold days later, after the intensity of the feelings is gone. (Korzenik, 1985, p. 2)

I find it equally true that if I can come to know three or four Tabasaran artists within the contexts of their villages, I too can share a deeper understanding of Tabasaran imagery.

Given my own background, it is easy to imagine that the Tabasaran had been so persistent in continuing their traditional art forms, resisting domination and control from outside groups. Their art continues to tell their community's constitutive story. Indeed, I am assured from my link in Moscow that even today each village has its own unique patterns. Undoubtedly some of the meanings associated with those patterns may have been lost, new ones may have been created, or even old meanings may have been rediscovered. In my own experience, the present generation, though it may perform some of the tasks of the old ways, has its own unique possibilities for action and for creating understanding. It would seem that each generation must ask its own questions, seek its own answers and to that end I seek to share the understanding of a few Tabasaran artists within present day reality.

\section{References}

Kerimov, L., Stepanian, N., Grigoliya, T., \& Tsitsishvili, D. (1984). Rugs and carpets from the Caucasus, the Russian collections. Leningrad: Aurora Art Publishers.

Korzenik, D. (1985). Drawn to Art. Hanover, NH: University Press of New England. 